\title{
Fear of Cancer Recurrence in Stomach Cancer Survivors: Exploring Socio-Demographic, Physical, Psychological and Quality of Life-Related Factors
}

Jinyoung Shin

Konkuk University School of Medicine

\section{Dong Wook Shin}

Sungkyunkwan University School of Medicine, Samsung Medical Center

Jungkwon Lee

Sungkyunkwan University School of Medicine, Samsung Medical Center

JiHye Hwang

Sungkyunkwan University School of Medicine, Samsung Medical Center

Ji Eun Lee

CHA Bundang Medical Center, CHA University

\section{BeLong Cho}

Seoul National University Hospital

Yun-Mi Song ( $\square$ yunmisong@skku.edu )

Samsung Medical Center, Sungkyunkwan University School of Medicine https://orcid.org/0000-00019232-5563

\section{Research article}

Keywords: Stomach neoplasms, survivor, fear, recurrence

Posted Date: April 3rd, 2021

DOI: https://doi.org/10.21203/rs.3.rs-378423/v1

License: (c) (i) This work is licensed under a Creative Commons Attribution 4.0 International License.

Read Full License 


\section{Abstract}

Background: This study aimed to evaluate factors related to the fear of cancer recurrence (FCR) in stomach cancer survivors.

Methods: A total of 363 stomach cancer survivors were divided into three groups according to the Korean version of the FCR Index (FCRI). We compared the socio-demographic and cancer-related factors, communication within the medical team during treatment, care coordination, social support, physical symptoms, psychological distress, and health-related quality of life (HRQoL), and health promotion and disease prevention activity, which was defined as second primary cancer screening, osteoporosis evaluation, supplementary drug intake, dietary pattern, regular exercise, and smoking cessation, according to the levels of FCRI using the linear regression analysis after adjusting for age, sex, stage, time since diagnosis, family cancer diagnosis, and comorbidities.

Results: An average of 7.3 years have passed since diagnosis. The highest FCRI group was younger or had a high percentage of family cancer diagnosis. Satisfaction for communication and care coordination, social support, HRQoL, and physical symptoms, such as fatigue, pain, and insomnia, were negatively associated with the FCR of stomach cancer survivors. Anxiety and depression were positively associated with the FCR. However, FCR was not associated with sex, time since diagnosis, cancer stage, treatment modality, socioeconomic status, or health promotion and disease prevention activity.

Conclusions: FCR in stomach cancer survivors was associated with physical, psychological, and HRQoL factors rather than socio-demographic or cancer-related factors. Understanding the association between HRQoL, physical and psychosocial factors, and FCR may advance survivorship care for stomach cancer survivors.

\section{Background}

Stomach cancer is the 5th most common neoplasm representing $5.7 \%$ of all new cancer cases and is the 3rd most deadly cancer, estimated 782,685 deaths according to GLOBOCAN 2018 data [1]. Stomach cancer is the most prevalent cancer in Korean males with aged 35-64 years, with an estimated 27,175 new cases in 2019 [2]. Meanwhile, the five-year survival rate for stomach cancer was 43.9 percent in 1993-1995, but, surprisingly, increased 32.6 percent to 76.5 percent in 2017 [3]. The survival rate for stomach cancer has probably improved due to an improved rate of early detection assisted by regular Korean national health examinations every two years and by advanced treatment technology based on accumulated clinical experience.

This improvement in survival rate suggests that we should not overlook stomach cancer survivors' problems. These survivors face various physical and psychosocial problems, such as anemia, bone disease, weight loss, and emotional distress [4]. Especially, fear of cancer recurrence (FCR) is one of the most prevalent unmet psychosocial needs related to psychological distress, functioning impairments, and increased use of health care resources [5]. Therefore, assessment of FCR and identifying relevant 
factors seem essential for cancer survivors' care [6]. Higher FCR is generally associated with younger age, higher education status, uncontrolled physical symptoms, and psychological distress [5, 7]. However, there were mixed findings for the associations with sex and marital status [5]. Furthermore, evidence of these associations was weak or inconclusive, depending on cancer type [6, 8].

Stomach cancer is known for being significantly influenced by behavioral and lifestyle risk factors [9]. Smoking, alcohol consumption, chemical exposure, obesity, and dietary factors (such as excessive salt intake) may be associated with the FCR of stomach cancer survivors and was considered a preventable condition [8-12]. Systematic reviews of 43 studies [8] and 130 studies [10] on the factors of FCR revealed that there are no stomach cancer-specific FCR publications.

Therefore, we conducted this study to evaluate the association of FCR of stomach cancer survivors with a range of factors including cancer-related information, socio-demographic characteristics, physical symptoms, psychological distress, social support and quality of life in Korean stomach cancer survivors. We further evaluated the effects of FCR on their health promotion and disease activity of Korean stomach cancer survivors.

\section{Methods}

\section{Study participants}

A total of 367 stomach cancer survivors with gastrectomy who visited a cancer survivorship clinic of a university-affiliated hospital in South Korea due to health problems or post-treatment surveillance after five years from initial cancer diagnosis was recruited from September 2014 to March 2017. The clinic has been involved in the care of a large number of Korean cancer patients. After excluding patients with metastasis at diagnosis $(n=4), 363$ stomach cancer survivors were analyzed in this study.

\section{Study variables}

We obtained data on Fear of Cancer Recurrence Index (FCRI) [6], health-related quality of life (HRQoL) [13], clinical and socio-demographic characteristics, satisfaction with communication within medical team and care coordination [14], functional social support [15], and health promotion and disease prevention activity using a self-administered questionnaire. If necessary, a trained research assistant completed incompletely answered questions through an additional face-to-face interview.

FCRI is a multidimensional questionnaire composed of 42 items with seven subscale components of FCR [16]. Potential stimuli activating FCR (triggers), presence and severity of intrusive thoughts associated with FCR (severity), emotional disturbance associated with FCR (psychological distress), impact of FCR on important areas of functioning (functional impairments), self-criticism toward FCR intensity (insight), and reassurance seeking such as thorough self-examination or repeated medical consultations (reassurance) and other strategies to cope with FCR (coping strategies) were evaluated. A total score of 
FCR ranges between 0 and 168. Cronbach's alpha coefficient for the FCRI-Korean version was 0.85 for the total scale and $0.77-0.87$ for the subscales [6].

The EuroQoL-visual analog scale (EQ-VAS) and the European Organization for Research and Treatment of Cancer Quality of Life Questionnaire version 3.0 (EORTC QLQ-C30) were used to assess HRQoL. The EQ-VAS is a standard vertical $20 \mathrm{~cm}$ visual analog scale for rating current HRQoL, ranging from zero (worst imaginable) to 100 (best imaginable). EORTC QLQ-C30 is a 30-item questionnaire developed to assess HRQoL of cancer patients incorporating five functional scales (physical, role, emotional, cognitive, and social), a nine-symptom scale (fatigue, nausea and vomiting, pain, dyspnea, insomnia, appetite loss, constipation, diarrhea, and financial difficulties), and a global quality of life scale. Participants responded using a four-point or a seven-point Likert scale. The score of each scale was calculated and ranged from zero to 100. Except for the cognitive functioning subscale, the Cronbach's alpha coefficients of the Korean version of the EORTC QLQ-C30 subscale are greater than 0.70 [13].

Fatigue severity scale (FSS) was developed to assess fatigue in patients with chronic diseases and included 10 questions that are rated from one (strongly disagree) to seven (strongly agree) [17]. A higher score denotes more severe fatigue. The Cronbach's a for total FSS was 0.935 , ranging from 0.925 to 0.932 for subscales [18]. Sleep problems were surveyed by a self-administered questionnaire. We assessed the level of sleep problems in terms of mean frequency: 1) no problems, 2) problems 1-2 nights per week, 3) problems 3-4 nights per week, and 4) problems every night. Anxiety and depressive mood were evaluated by the Hospital Anxiety and Depression Scale (HADS, range 0-21). The Cronbach's a of the Korean version of HADS was 0.89 for the anxiety subscale and 0.86 for the depression subscale [19].

Socio-demographic characteristics were obtained using a self-administered questionnaire: monthly income level ( $\geq 4,000,000$ won per month, 2,000,000-3,999,999, and $<2,000,000)$, achieved education level ( $\leq 9$ years, $10-12$, and $\geq 13$ ), marital status (married/with a partner and unmarried/without a partner), family cancer diagnosis (spouse, 1 st degree relatives, or none), and religion (yes or no). We reviewed their medical records for cancer-related information, such as time since cancer diagnosis, cancer stage, additional treatment modality (chemotherapy, and/or radiotherapy), and Carlson's comorbidity index, which was calculated using 18 conditions, excluding age [20].

Satisfaction with the level of communication on harmony, interaction, and role responsibility within the medical team was assessed with five points each for a possible total of 15 points. A higher score equates to a higher level of dissatisfaction with communication within the medical team. Care coordination assessment was based on this question: "Did you receive all care services that were necessary for dealing with your health concern during the cancer treatment period?" [14]. Scoring ranged from one to five, and a higher score equated to a higher level of dissatisfaction with care coordination. We measured the person's perceived need for a social support network by the Duke-UNC functional social support questionnaire (FSSQ) [15]. The questionnaire was composed of eight-items from two subscales, confidant and effective support, with five answer choices ranging from five ('As much as I would like') to 
one ('Much less than I would like') [21]. We presented the average score of the eight responses. The Cronbach's a of the Korean version of the FSSQ was 0.89 [22].

To evaluate health promotion and disease activity, data on receipt of the second primary cancer screening test (colonoscopy, mammography, and Pap smear), patterns for smoking, drinking, and exercise, bone mineral density evaluation within two years, supplementary drug intake, and dietary pattern changes after cancer diagnosis were collected by self-administered questionnaire. Quitting of smoking and drinking was evaluated for occurrence after a cancer diagnosis or treatment. Regular exercise was defined as at least one time per week for 30 minutes. Supplementary drug intake was defined as consistently (more than 2 weeks) taking supplements such as vitamin B complex, vitamin C, vitamin D, multivitamins, calcium, and iron after a cancer diagnosis. Dietary pattern changes after cancer diagnosis were evaluated by asking whether the frequency of intake increased or decreased for organic food, fruit or vegetables, pork or beef, processed meat, and salty food.

\section{Statistical analysis}

Descriptive statistics of study participants were expressed as mean value \pm standard deviation for continuous variables and number (proportion) for categorical variables. Because a cut-off point score for identifying people with abnormally high FCR has not been determined, the level of FCR was divided into tertile (lowest/middle/highest groups) of the FCRI summed score of triggers, severity, distress, functional impairment, and insight subscales. The differences in cancer-related information and socio-demographic variables according to tertile of FCRI score were compared by one-way ANOVA analysis, chi-square test, or Fisher's exact test. The satisfaction of communication with a medical team and care coordination and the mean levels of FSSQ were compared using a linear regression analysis with an adjustment for selected covariates [6]. We presented the mean scores of HRQoL measured by EQ-VAS and EORTC QLQC30 and the level of fatigue severity, sleep problems, anxiety, and depression according to the tertile of FCR. We evaluated the relationship between health promotion and disease prevention and the level of FCRI using a multiple logistic regression analysis after adjusting for age, sex, cancer stage, Carlson's Comorbidity Index, time since diagnosis, family cancer diagnosis, Duke FSSQ, and satisfaction with communication within a medical team and of care coordination. All statistical analyses were performed using IBM SPSS Statistics for Windows, version 24.0 (IBM Corp., Armonk, NY, USA).

\section{Results}

Table 1 shows the general characteristics of study participants $(n=363)$. The mean age of subjects was 56.9 years old, with an average of 7.3 years since diagnosis. Two-thirds of subjects were on stage I and $61.7 \%$ of subjects performed surgical treatment only. Table 2 shows the related factors with FCRI in stomach cancer survivors according to the tertile level of FCRI. Younger survivors were more likely to be classified into the highest group of FCRI. A spouse or $1^{\text {st }}$ degree relatives was diagnosed with cancer in the highest FCR group. A higher FCRI level was associated with unsatisfaction of communication and care coordination and less social support. There were no significant differences in the time since cancer 
diagnosis, sex, income, education, marital status, religion, cancer stage, treatment modality, and comorbidity according to the level of FCRI.

Figure 1 shows the distribution of HRQoL, physical, and psychosocial factors according to the level of FCRI. Compared to subjects in the lowest tertile, those of the highest tertile of FCRI showed worse HRQoL. The trend of EQ-VAS and the global health status and functional scales of EORTC QLQ-C30 were significantly lower in the highest tertile group (Figure 1- (A)). The symptom scales of EORTC QLQ-C30 (fatigue, nausea and vomiting, pain, dyspnea, and insomnia) and financial difficulty were significantly higher in the highest tertile of FCRI (Figure 1- (B)). A similar direction lacking statistical significance was observed for appetite loss, constipation, and diarrhea (Figure 1- (B)). Fatigue severity scale, sleep problems, anxiety, and depression were also higher in the highest FCRI group (Figure 1- (C)).

Table 3 shows the relationship between the health promotion and disease prevention activity and FCRI. There was no difference in the pursuit of second primary cancer screening, such as colonoscopy, mammography and Pap smear test in female, smoking status, alcohol intake, exercise, bone mineral density measurement for osteoporosis evaluation, supplementary drug intake, and dietary pattern changes across levels of FCRI after adjusting for age, sex, cancer stage, Carlson's Comorbidity Index, duration since cancer diagnosis, family cancer diagnosis, Duke functional social support and satisfaction for communication within medical team and care coordination.

\section{Discussion}

In this study, the presence of uncontrolled physical symptoms, psychological distress, and poor HRQoL was associated with high FCR in stomach cancer survivors even after adjusting for covariates. Functional social support and satisfaction for communication within the medical team and care coordination were negatively associated with the FCR. However, FCR was found to have no relationship with cancer-related or socio-demographic factors, except age and health promotion or disease prevention activity of stomach cancer survivors.

Like other cancer patients, stomach cancer survivors who are younger, with uncontrolled physical symptoms, psychological distress, and lower HRQoL were associated with higher FCR [10]. In a previous study with 342 Chinese breast cancer survivors who were diagnosed less than 2 years $(67.3 \%$ of the total number of subjects), between 2 and 3 years (14.0\%), and more than 3 years (18.7\%), no religious beliefs, lower family income, and treatment modality (breast-conserving surgery) were associated with the higher level of FCR, unlike our result [23]. The differences in our FCR effects may be due to the diagnosis period; this study has a long time (average of 7.3 years) since its diagnosis. In general, breast cancer patients are often easily affected by psychological and social factors and have a higher level of FCR [24]. We confirmed the relationship between social supports, social and emotional quality of life, and levels of FCR in stomach cancer survivors. Because social support was related to predicting mood, coping strategies, and positive adjustment in cancer survivors [25-27], it should be considered in understanding FCR. But it 
has to be interpreted with caution as different results may be arisen depending on cultural differences of a family-dependent nature, age, perceived support level, or family roles [27, 28].

Null associations were identified for gender and education level in this study. In Canadian patients with breast, prostate, lung, and colorectal cancer, the FCRI for female cancer survivors was high [29]. However, this finding did not hold after controlling for the cancer type. Although further research is needed when there is not enough gender-specific research, the systematic review of 43 studies reported that gender appeared unrelated to FCR [8]. However, recent studies of hematologic cancer patients, including 467 Korean lymphoma patients, reported that female patients had a greater FCR than male patients [28, 30]. Stomach cancer is one of the cancers with a good survival rate. Since $85 \%$ of the study participants were stage 1 or 2, the five-year survival rate is increased up to $97.4 \%$ in 2017 [3]. On the other hand, the fiveyear survival rate of the Korean non-Hodgkin lymphoma patients is $63.8 \%$ in the same year [3]. We thought that there may be a gender gap of FCR because a relatively poor prognosis can be vulnerable to emotion $[28,31]$. Regarding the relationship between education and FCR, FCR was associated with a lower education level in 89 American breast cancer patients [32]. There was a suggestion for the role of education that highly educated patients may have a greater understanding of the implications of cancer diagnosis [8]. However, the lack of relevance between FCR and education levels in this study is that the role of education may have been relatively insignificant as long-term survivors who do not need the understanding of cancer diagnosis.

Several studies revealed no association between FCR and the influence of treatment type and duration, and stage of the disease $[10,28]$. However, physical and psychological symptoms, such as fatigue, pain, sleep problems, distress, anxiety, and depression, were strongly associated with FCR regardless of cancer type or time since cancer diagnosis [10]. We suggest that this is also due to the nature of FCR in longterm survivors of cancer on the effect of uncontrolled physical and psychological symptoms $[6,10,24]$. Therefore, continuing interest to control their physical and psychological problems is important in aspects of both FCR management and care coordination [14].

It was a noticeable finding that FCR was associated with the satisfaction of care coordination in stomach cancer survivors, which is compatible with the findings of a previous study in 2,290 non-metastatic multi-ethnic breast cancer patients [33]. Well-coordinated care may reflect a good relationship between patients and healthcare providers. A provision of proper coaching or strategies for FCR from the healthcare providers would have lowered the level of FCR [14]. Additionally, whole-person care and tailored patient education for lifestyle modification may reduce the development of comorbidities and prevent late adverse effects after cancer diagnosis [34].

However, survivors' health promotion and disease prevention activities were not associated with the level of FCR in this study. Even in survivors with high FCR, lifestyle modification, secondary primary cancer screening, and surveillance of comorbidities were unaffected. These findings do not support the 'teachable moment theory,' suggesting that cancer survivors who experience greater FCR are motivated to engage in health behaviors $[11,35]$. This theory has worked in the case of smoking cessation [36]. 
However, the theory does not apply to the health behaviors of cancer survivors because FCR severity may neither encourage nor hinder most survivors [11]. Cancer survivors with high FCR may experience high levels of distress and may not adhere to healthy lifestyle recommendations [37]. For example, a study in the United States found that survivors of breast, gynecologic, colorectal, and non-melanoma skin cancers with high FCR were twice more likely to smoke as those with no FCR and didn't do enough exercise (half an hour or more at least five times a week) [38]. To explain this, we propose the following: that most cancer survivors try to improve their health behaviors regardless of the level of FCR. The practice of healthier habits defined as any positive activities concerning cancer or treatment was found to have doubled after cancer diagnosis regardless of the level of FCR in US survivors [38]. Additionally, the rate of unhealthy behaviors in our study was too low to compare for significant differences across the different FCR groups; the proportion of current smokers in our study was much lower $(0.4 \%)$ compared to that (14\%) of the United States study [38]. Last, the effect of FCR on health behaviors may be motivational for a certain period of time only or during a treatment period. It was known that FCR stabilizes over time [10]. Therefore, there was no association between FCR and health promotion and disease prevention activities for long-term survivors [39]. Unfortunately, we did not find the variance between time since diagnosis and FCR in this study.

The present study has some limitations. First, our study results may not be generalizable to all stomach cancer survivors because this study was conducted in one academic hospital. However, this hospital is involved in cancer care for more than $10 \%$ of all Korean cancer patients. Many cancer patients in South Korea have been conducting regular medical examination at the hospital, taking gastrectomy for more than five years [40]. Second, this study was conducted using a cross-sectional study design with information collected simultaneously; we cannot ensure the time relationships between FCR and satisfaction of communication and care coordination and health promotion and disease prevention activities. Third, we assessed HRQoL, physical and psychosocial factors, and health behaviors through self-report questionnaires. Data are susceptible to recall bias and bias due to social desirability because of non-objective observation [41]. Fourth, we could not compare the effect of treatment modality, e.g., endoscopic treatment and surgical treatment, on FCR, because the number of patients receiving endoscopic treatment was small $(n=6)$. In a previous study, endoscopic treatment of early esophageal cancer had a less negative impact on the quality of life and physical symptoms than open surgery [42]. Considering the effect of uneven treatment status, our participants were limited to stomach cancer survivors with gastrectomy. Last, it was not clear whether distinguishing FCR levels from tertile value of FCRI meant actual clinical FCR because there was no known cut-off value of FCRI. Although the FCRIshort form including nine items, presents 22 points as cut-off, experts have said that this value may not be applied to other populations of cancer survivors. Therefore, further study was needed to explore the clinical cut-off points in Korean stomach cancer survivors.

Nevertheless, this study is the first to study to evaluate the related factors with FCR in stomach cancer survivors and has the strength to consider a wide range of factors, including clinical and sociodemographic characteristics, physical symptoms, psychological distress, and quality of life. 


\section{Conclusions}

The present study confirmed the association between FCR of stomach cancer survivors and physical symptoms, psychological distress, social support, HRQoL, and satisfaction for communication within the medical team and care coordination. These findings will help better understand the FCR of stomach cancer survivors and make a survivorship care plan.

\section{Abbreviations}

FCR: Fear of cancer recurrence

FCRI: Fear of cancer recurrence index

HRQoL: Health-related quality of life

EQ-VAS: The EuroQoL-visual analog scale

EORTC QLQ-C30: the European Organization for Research and Treatment of Cancer Quality of Life Questionnaire version 3.0

FSS: Fatigue severity scale

HADS: Hospital Anxiety and Depression Scale

FSSQ: Functional social support questionnaire

\section{Declarations}

\section{Ethics approval and consent to participate}

All procedures performed in studies involving human participants were in accordance with the ethical standards of the institutional and/or national research committee and with the 1964 Helsinki declaration and its later amendments or comparable ethical standards. This study was approved by the Institutional Review Board (IRB) of Samsung Medical Center approved the study protocol (IRB file no. SMC2015-03045).

The written informed consent was obtained from all individual participants included in the study.

\section{Availability of data and materials}

The datasets used and/or analysed during the current study are available from the corresponding author on reasonable request.

Competing interests 
None of the authors have financial or non-financial competing interests to declare.

\section{Funding}

This study was supported by a grant of the National R\&D Program for Cancer Control funded by the Ministry of Health \& Welfare, Republic of Korea (1720270). The funding source had no involvement in the study design, data collection, data analysis, or data interpretation of this study.

\section{Authors' contributions}

JS, DWS, JL, and YMS conceptualized the research idea. JS, DWS, JL, JHH, JEL, BLC, and YMS participated in data collection, data analysis, and interpretation. JS and YMS drafted and DWS, JL, JHH, JEL, and BLC reviewed and corrected the language expression. YMS obtained funding. All authors have read and approved the manuscript.

\section{References}

1. Bray F, Ferlay J, Soerjomataram I, Siegel RL, Torre LA, Jemal A. Global cancer statistics 2018 : GLOBOCAN estimates of incidence and mortality worldwide for 36 cancers in 185 countries. Cancer J Clin. 2018;68(6):394-424.

2. Jung KW, Won YJ, Kong HJ, Lee ES. Prediction of Cancer Incidence and Mortality in Korea, 2019. Cancer research treatment: official journal of Korean Cancer Association. 2019;51(2):431-7.

3. Hong S, Won YJ, Park YR, Jung KW, Kong HJ, Lee ES. Cancer Statistics in Korea: Incidence, Mortality, Survival, and Prevalence in 2017. Cancer research treatment: official journal of Korean Cancer Association. 2020;52(2):335-50.

4. Kang J, Park EJ, Lee J. Cancer Survivorship in Primary Care. Korean J Fam Med. 2019;40(6):353-61.

5. Crist JV, Grunfeld EA. Factors reported to influence fear of recurrence in cancer patients: a systematic review. (1099-1611 (Electronic)).

6. Shin J, Goo A, Ko H, Kim JH, Lim SU, Lee HK, Simard S, Song YM. Validation Study for the Korean Version of Fear of Cancer Recurrence Inventory. J Korean Med Sci. 2017;32(11):1792-9.

7. Mahendran R, Liu J, Kuparasundram S, Simard S, Chan YH, Kua EH, Griva K. Fear of cancer recurrence among cancer survivors in Singapore. Singapore medical journal 2020.

8. Crist JV, Grunfeld EA. Factors reported to influence fear of recurrence in cancer patients: a systematic review. Psycho-oncology. 2013;22(5):978-86.

9. International WCRF: Continuous update project report: diet, nutrition, physical activity, and prostate cancer. In.: World Cancer Research Fund International London, UK; 2014.

10. Simard S, Thewes B, Humphris G, Dixon M, Hayden C, Mireskandari S, Ozakinci G. Fear of cancer recurrence in adult cancer survivors: a systematic review of quantitative studies. Journal of cancer survivorship: research practice. 2013;7(3):300-22. 
11. Seguin Leclair C, Lebel S, Westmaas JL. The relationship between fear of cancer recurrence and health behaviors: A nationwide longitudinal study of cancer survivors. Health psychology: official journal of the Division of Health Psychology American Psychological Association. 2019;38(7):596605.

12. Tsugane S, Sasazuki S. Diet and the risk of gastric cancer: review of epidemiological evidence. Gastric cancer: official journal of the International Gastric Cancer Association the Japanese Gastric Cancer Association. 2007;10(2):75-83.

13. Yun YH, Park YS, Lee ES, Bang SM, Heo DS, Park SY, You CH, West K. Validation of the Korean version of the EORTC QLQ-C30. Quality of life research: an international journal of quality of life aspects of treatment care rehabilitation. 2004;13(4):863-8.

14. Shin J, Shin DW, Lee J, Hwang JH, Yoo JE, Ko H, Song YM. Association between perception of care coordination and health outcomes in Korean cancer survivors. Health Qual Life Outcomes. 2020;18(1):21.

15. Broadhead WE, Gehlbach SH, de Gruy FV, Kaplan BH. The Duke-UNC Functional Social Support Questionnaire. Measurement of social support in family medicine patients. Medical care. 1988;26(7):709-23.

16. Lebel S, Simard S, Harris C, Feldstain A, Beattie S, McCallum M, Lefebvre M, Savard J, Devins GM: Empirical validation of the English version of the Fear of Cancer Recurrence Inventory. Quality of life research: an international journal of quality of life aspects of treatment, care and rehabilitation 2015.

17. Krupp LB, LaRocca NG, Muir-Nash J, Steinberg AD. The fatigue severity scale. Application to patients with multiple sclerosis and systemic lupus erythematosus. Arch Neurol. 1989;46(10):1121-3.

18. Chung K-I, Song C-HJKjopm. Clinical usefulness of fatigue severity scale for patients with fatigue, and anxiety or depression. 2001, 9(2):164-173.

19. Oh SM, Min KJ, Park DB. A study on the standardization of the hospital anxiety and depression scale for Koreans: a comparison of normal, depressed and anxious groups. 1999, 38(2):289-296.

20. D'Hoore W, Sicotte C, Tilquin C. Risk adjustment in outcome assessment: the Charlson comorbidity index. Methods of information in medicine 1993, 32(5):382-387.

21. FSSQ, Duke-UNC Functional Social Support Questionnaire http://adultmeducation.com/AssessmentTools_4.html.

22. Suh SY, Im YS, Lee SH, Park MS. Yoo TJJotKAoFM: A study for the development of Korean version of the Duke-UNC functional social support questionnaire. 1997, 18(3):250-260.

23. Niu L, Liang Y, Niu M. Factors influencing fear of cancer recurrence in patients with breast cancer: Evidence from a survey in Yancheng, China. J Obstet Gynaecol Res. 2019;45(7):1319-27.

24. Gotze H, Taubenheim S, Dietz A, Lordick F, Mehnert-Theuerkauf A. Fear of cancer recurrence across the survivorship trajectory: Results from a survey of adult long-term cancer survivors. Psychooncology. 2019;28(10):2033-41.

25. Ell K, Nishimoto R, Mediansky L, Mantell J, Hamovitch M. Social relations, social support and survival among patients with cancer. J Psychosom Res. 1992;36(6):531-41. 
26. Cicero V, Lo Coco G, Gullo S, Lo Verso G. The role of attachment dimensions and perceived social support in predicting adjustment to cancer. Psycho-oncology. 2009;18(10):1045-52.

27. Thewes B, Bell ML, Butow P, Beith J, Boyle F, Friedlander M, McLachlan SA. Psychological morbidity and stress but not social factors influence level of fear of cancer recurrence in young women with early breast cancer: results of a cross-sectional study. Psycho-oncology. 2013;22(12):2797-806.

28. Borreani C, Alfieri S, Farina L, Bianchi E, Corradini P: Fear of cancer recurrence in haematological cancer patients: exploring socio-demographic, psychological, existential and disease-related factors. Supportive care in cancer: official journal of the Multinational Association of Supportive Care in Cancer 2020, 28(12):5973-5982.

29. Simard S, Savard J. Fear of Cancer Recurrence Inventory: development and initial validation of a multidimensional measure of fear of cancer recurrence. Supportive care in cancer: official journal of the Multinational Association of Supportive Care in Cancer. 2009;17(3):241-51.

30. Kim SJ, Kang D, Kim IR, Yoon SE, Kim WS, Butow PN, Guallar E, Cho J. Impact of fear of cancer recurrence on survival among lymphoma patients. Psycho-oncology. 2020;29(2):364-72.

31. Kret ME, De Gelder B. A review on sex differences in processing emotional signals. Neuropsychologia. 2012;50(7):1211-21.

32. Costanzo ES, Lutgendorf SK, Mattes ML, Trehan S, Robinson CB, Tewfik F, Roman SL. Adjusting to life after treatment: distress and quality of life following treatment for breast cancer. British journal of cancer. 2007;97(12):1625-31.

33. Janz NK, Hawley ST, Mujahid MS, Griggs JJ, Alderman A, Hamilton AS, Graff JJ, Jagsi R, Katz SJ. Correlates of worry about recurrence in a multiethnic population-based sample of women with breast cancer. Cancer. 2011;117(9):1827-36.

34. Chumbler NR, Kobb R, Harris L, Richardson LC, Darkins A, Sberna M, Dixit N, Ryan P, Donaldson M, Kreps GL. Healthcare utilization among veterans undergoing chemotherapy: the impact of a cancer care coordination/home-telehealth program. J Ambul Care Manag. 2007;30(4):308-17.

35. Demark-Wahnefried W, Aziz NM, Rowland JH, Pinto BM. Riding the crest of the teachable moment: promoting long-term health after the diagnosis of cancer. Journal of clinical oncology: official journal of the American Society of Clinical Oncology. 2005;23(24):5814-30.

36. McBride CM, Emmons KM, Lipkus IM. Understanding the potential of teachable moments: the case of smoking cessation. Health Educ Res. 2003;18(2):156-70.

37. Mutsaers B, Jones G, Rutkowski N, Tomei C, Seguin Leclair C, Petricone-Westwood D, Simard S, Lebel $\mathrm{S}$. When fear of cancer recurrence becomes a clinical issue: a qualitative analysis of features associated with clinical fear of cancer recurrence. Supportive care in cancer: official journal of the Multinational Association of Supportive Care in Cancer. 2016;24(10):4207-18.

38. Reed SC, Bell JF, Miglioretti DL, Nekhlyudov L, Fairman N, Joseph JG. Relationships Between Fear of Cancer Recurrence and Lifestyle Factors Among Cancer Survivors. J Cancer Educ 2019.

39. Williams K, Steptoe A, Wardle J. Is a cancer diagnosis a trigger for health behaviour change? Findings from a prospective, population-based study. Br J Cancer. 2013;108(11):2407-12. 
40. Lee JE, Shin DW, Lee H, Son KY, Kim WJ, Suh Y-S, Kong S-H, Lee HJ, Cho B, Yang H-K. One-Year Experience Managing a Cancer Survivorship Clinic Using a Shared-Care Model for Gastric Cancer Survivors in Korea. J Korean Med Sci. 2016;31(6):859-65.

41. Paulhus DL. In Measures of Personality and Social Psychological Attitudes. San Diego: Academic Press; 1991.

42. Rosmolen WD, Nieuwkerk PT, Pouw RE, van Berge Henegouwen MI, Bergman JJ, Sprangers MA. Quality of life and fear of cancer recurrence after endoscopic treatment for early Barrett's neoplasia: a prospective study. Diseases of the esophagus: official journal of the International Society for Diseases of the Esophagus. 2017;30(3):1-9.

\section{Tables}

Table 1. General characteristics of study participants $(n=363)$ 


\begin{tabular}{|c|c|}
\hline Variables & $\begin{array}{l}\text { Mean } \pm \text { SD or } \\
\text { Number (\%) }\end{array}$ \\
\hline Age at survey, years & $56.9 \pm 9.6$ \\
\hline Age at cancer diagnosis, years & $49.6 \pm 9.7$ \\
\hline Time since cancer diagnosis, years & $7.3 \pm 3.2$ \\
\hline \multicolumn{2}{|l|}{ Sex } \\
\hline Male & $193(53.2)$ \\
\hline Female & $170(46.8)$ \\
\hline \multicolumn{2}{|l|}{ Household income (won/month) } \\
\hline$\geq 4,000,000$ & $167(46.0)$ \\
\hline $2,000,000-3,999,999$ & $108(29.8)$ \\
\hline$<2,000,000$ & $88(24.2)$ \\
\hline \multicolumn{2}{|l|}{ Achieved education level } \\
\hline $0-9$ years & 65 (17.9) \\
\hline $10-12$ years & $141(38.8)$ \\
\hline$\geq 13$ years & $157(43.3)$ \\
\hline \multicolumn{2}{|l|}{ Marital status } \\
\hline Married/with partner & 317 (87.3) \\
\hline Unmarried/without partner & $46(12.7)$ \\
\hline \multicolumn{2}{|l|}{ Ffamily cancer diagnosis } \\
\hline Spouse & $14(3.9)$ \\
\hline $1^{\text {st }}$ degree relatives & $153(42.1)$ \\
\hline None & $189(52.1)$ \\
\hline \multicolumn{2}{|l|}{ Religion } \\
\hline Yes & $247(68.0)$ \\
\hline No & $116(32.0)$ \\
\hline \multicolumn{2}{|l|}{ Cancer stage } \\
\hline I & $242(66.7)$ \\
\hline II & $67(18.5)$ \\
\hline
\end{tabular}

Page 14/21 


\begin{tabular}{|l|l|}
\hline III & $54(14.9)$ \\
\hline Oreatment modality & \\
\hline Surgery + Chemotherapy & $224(61.7)$ \\
\hline Surgery + Chemotherapy + Radiotherapy & $79(21.8)$ \\
\hline Carlson Comorbidity Index $\neq$ & \\
\hline 0 & $315(86.8)$ \\
\hline 1 & $35(9.6)$ \\
\hline$\geq 2$ & $13(3.6)$ \\
\hline
\end{tabular}

FCRI: Fear of Cancer Recurrence Inventory, SD: standard deviation

Table 2. Factors associated with Fear of Cancer Recurrence Inventory score in stomach cancer survivors 


\begin{tabular}{|c|c|c|c|c|c|}
\hline \multirow[t]{2}{*}{ Variables } & \multicolumn{3}{|c|}{ Level of FCRI score $\dagger$} & \multirow{2}{*}{$\begin{array}{l}\text { Beta } \\
\text { coefficients }\end{array}$} & \multirow{2}{*}{$\begin{array}{l}\text { P- } \\
\text { value* }\end{array}$} \\
\hline & $\begin{array}{l}\text { Lowest } \\
(0-24)\end{array}$ & $\begin{array}{l}\text { Middle } \\
\text { (24.1- } \\
41.1)\end{array}$ & $\begin{array}{l}\text { Highest } \\
(41.1-104)\end{array}$ & & \\
\hline $\mathrm{n}$ & 124 & 113 & 126 & & \\
\hline Age at survey, years & $58.4 \pm 9.6$ & $57.3 \pm 8.8$ & $54.9 \pm 10.1$ & -0.156 & 0.003 \\
\hline Age at cancer diagnosis, years & $51.2 \pm 9.5$ & $50.0 \pm 9.0$ & $47.7 \pm 10.3$ & -0.143 & 0.006 \\
\hline $\begin{array}{l}\text { Time since cancer diagnosis, } \\
\text { years }\end{array}$ & $7.2 \pm 3.0$ & $7.6 \pm 3.4$ & $7.0 \pm 3.1$ & -0.030 & 0.561 \\
\hline Sex & & & & 0.059 & 0.259 \\
\hline Male & $71(36.8)$ & $59(30.6)$ & $63(32.6)$ & & \\
\hline Female & $53(31.2)$ & $54(31.8)$ & $63(37.1)$ & & \\
\hline Household income (won/month) & & & & -0.022 & 0.695 \\
\hline$\geq 4,000,000$ & $57(34.1)$ & $52(32.7)$ & $58(32.7)$ & & \\
\hline $2,000,000-3,999,999$ & $37(34.3)$ & $35(32.4)$ & 36(33.3) & & \\
\hline$<2,000,000$ & $30(34.1)$ & $26(29.5)$ & $32(36.4)$ & & \\
\hline Achieved education level & & & & 0.057 & 0.297 \\
\hline $0-9$ years & $26(40.0)$ & 18(27.7) & 21(32.3) & & \\
\hline $10-12$ years & $46(32.6)$ & $47(33.3)$ & $48(34.0)$ & & \\
\hline$\geq 13$ years & $50(31.8)$ & $47(29.9)$ & $60(38.2)$ & & \\
\hline Marital status & & & & -0.044 & 0.547 \\
\hline Married/with partner & 107(33.7) & $96(30.3)$ & 114(36.0) & & \\
\hline Unmarried/without partner & 17(37.0) & $17(37.0)$ & $12(26.0)$ & & \\
\hline Family cancer diagnosis & & & & 0.124 & 0.017 \\
\hline Spouse & $6(42.9)$ & 0 & $8(57.1)$ & & \\
\hline $1^{\text {st }}$ degree relatives & $45(29.4)$ & $51(33.3)$ & $57(37.3)$ & & \\
\hline None & 74(39.2) & $58(30.7)$ & $57(30.1)$ & & \\
\hline Religion & & & & 0.059 & 0.260 \\
\hline Yes & 82(33.2) & $73(29.6)$ & $92(37.2)$ & & \\
\hline No & $42(36.2)$ & $40(34.5)$ & $34(29.3)$ & & \\
\hline Cancer stage & & & & 0.010 & 0.844 \\
\hline
\end{tabular}




\begin{tabular}{|c|c|c|c|c|c|}
\hline I & $83(34.3)$ & $79(32.6)$ & 80(33.1) & & \\
\hline II & 23(34.3) & $17(25.4)$ & $27(40.3)$ & & \\
\hline III & 18(33.3) & $17(31.5)$ & $19(35.2)$ & & \\
\hline Treatment modality & & & & 0.015 & 0.770 \\
\hline Only surgery & $76(33.8)$ & $73(34.2)$ & $75(32.0)$ & & \\
\hline Surgery + Chemotherapy & $20(32.3)$ & 17(32.3) & $23(35.4)$ & & \\
\hline $\begin{array}{l}\text { Surgery + Chemotherapy + } \\
\text { Radiotherapy }\end{array}$ & $28(35.9)$ & $23(32.1)$ & $28(32.1)$ & & \\
\hline Carlson Comorbidity Index $\ddagger$ & & & & 0.040 & 0.441 \\
\hline 0 & $110(34.9)$ & $96(30.5)$ & $109(34.6)$ & & \\
\hline 1 & $12(34.3)$ & 11(31.4) & $12(34.3)$ & & \\
\hline$\geq 2$ & $2(15.4)$ & $6(46.2)$ & $5(38.5)$ & & \\
\hline $\begin{array}{l}\text { Unsatisfaction with } \\
\text { communication (range: } 3-15 \text { ) }\end{array}$ & $4.0 \pm 1.8$ & $4.2 \pm 1.9$ & $4.6 \pm 1.8$ & 0.108 & $0.038^{9}$ \\
\hline $\begin{array}{l}\text { Unsatisfaction with care } \\
\text { coordination (range: } 1-5) \S\end{array}$ & $1.6 \pm 0.8$ & $1.7 \pm 0.9$ & $1.9 \pm 0.9$ & 0.118 & $0.023^{4}$ \\
\hline $\begin{array}{l}\text { Functional social support, mean } \\
\text { (range:1-8)§ }\end{array}$ & $3.2 \pm 1.0$ & $3.2 \pm 1.0$ & $2.7 \pm 0.9$ & -0.211 & $<0.001^{9}$ \\
\hline $\begin{array}{l}\text { Sum of confidant support } \\
\text { (range:5-25)§ }\end{array}$ & $16.0 \pm 3.4$ & $16.0 \pm 3.9$ & $13.4 \pm 3.7$ & -0.194 & $<0.001^{9}$ \\
\hline $\begin{array}{l}\text { Sum of affective support (range:3- } \\
15)^{\S}\end{array}$ & $12.4 \pm 2.6$ & $12.2 \pm 2.5$ & $9.6 \pm 2.8$ & -0.232 & $<0.001^{9}$ \\
\hline
\end{tabular}

Data are presented as mean values and standard deviations, or number (percentage).

FCRI, Fear of Cancer Recurrence Inventory. Data were presented as mean value \pm standard deviation or number (row percentage). *P values were obtained by one-way analysis of variance test, chi-square test, or Fisher's exact test. †Total score was calculated after excluding the coping and reassurance domain. $\ddagger$ In the Carlson Comorbidity Index, age and cancer were excluded. §̧Higher score means a higher level of agreement

१P-value was assessed using a linear regression analysis after adjusting for age, sex, cancer stage, Carlson's Comorbidity Index, family cancer diagnosis and time since cancer diagnosis. FCRI score was included as a response variable in the analytic model. 
Table 3. The relation between health promotion and disease prevention activity and the level of FCRI in stomach cancer survivors 
Odd ratio (95\% confidence intervals)

$P$-for trend*

Lowest Middle Highest

FCRI FCRI FCRI

\section{Secondary primary cancer screening}

Colonoscopy

$1 \quad 1.02(0.48,2.18) \quad 1.04(0.49,2.20) \quad 0.994$

Mammography (female)

1

$0.53(0.20,1.40)$

$0.81(0.29,2.29)$

0.401

Pap smear (female)

$1 \quad 0.87(0.33,2.24)$

$1.27(0.47,3.40)$

0.730

\section{Smoking status}

Current smoking

1

$0.98(0.05,19.43)$

$2.04(0.14,30.96)$

0.833

Quitting smoking after cancer diagnosis 1

$1 \quad 0.75(0.28,2.02)$

$0.71(0.27,1.87)$

0.755

Current alcohol intake, $\geq 7 \mathrm{~g} /$ week

1

$0.31(0.08,1.29)$

$0.79(0.20,3.14)$

0.141

Quitting drinking after cancer diagnosis 1

Regular exercise $\geq$ One time/week and $\geq \quad 1$ $30 \mathrm{~min} /$ day

$1.13(0.35,3.62)$

$0.95(0.27,3.42)$

0.963

\section{Bone mineral density measurement}

Total subjects

1

$1.07(0.47,2.41)$

$1.80(0.77,4.17)$

0.326

Postmenopausal women and elderly men ( $\geq 70$ years)

1

0.82(0.34,1.97)

1.02(0.42,2.47)

0.860

\section{Supplementary drug intake for 2 weeks or longer} after a cancer diagnosis

\begin{tabular}{lllll} 
Vitamins & 1 & $0.24(0.06,0.93)$ & $0.29(0.07,1.12)$ & 0.072 \\
Calcium & 1 & $0.28(0.04,1.85)$ & $0.49(0.09,2.69)$ & 0.390 \\
\hline Iron & 1 & $0.23(0.03,1.92)$ & $1.20(0.21,6.99)$ & 0.262
\end{tabular}

\section{Dietary pattern changes}

\begin{tabular}{lcccc} 
Increased organic food intake & 1 & $0.80(0.35,1.83)$ & $1.06(0.47,2.41)$ & 0.776 \\
Increased fruit intake & 1 & $0.54(0.23,1.24)$ & $0.70(0.30,1.64)$ & 0.345 \\
Increased vegetables intake & 1 & $0.74(0.33,1.70)$ & $0.65(0.28,1.52)$ & 0.599 \\
\hline Reduced pork or beef intake & 1 & $1.09(0.49,2.43)$ & $1.11(0.49,2.52)$ & 0.966 \\
Reduced processed meat intake & 1 & $0.40(0.13,1.28)$ & $1.05(0.91,1.22)$ & 0.200 \\
Reduced salty food intake & 1 & $0.83(0.33,2.07)$ & $0.84(0.33,2.16)$ & 0.908 \\
\hline
\end{tabular}


* Odds ratio were obtained using multiple logistic regression analysis after adjusting for age, sex, cancer stage, Carlson's Comorbidity Index, time since diagnosis, family cancer diagnosis, Duke functional social support, and satisfaction for communication within a medical team and care coordination.

\section{Figures}
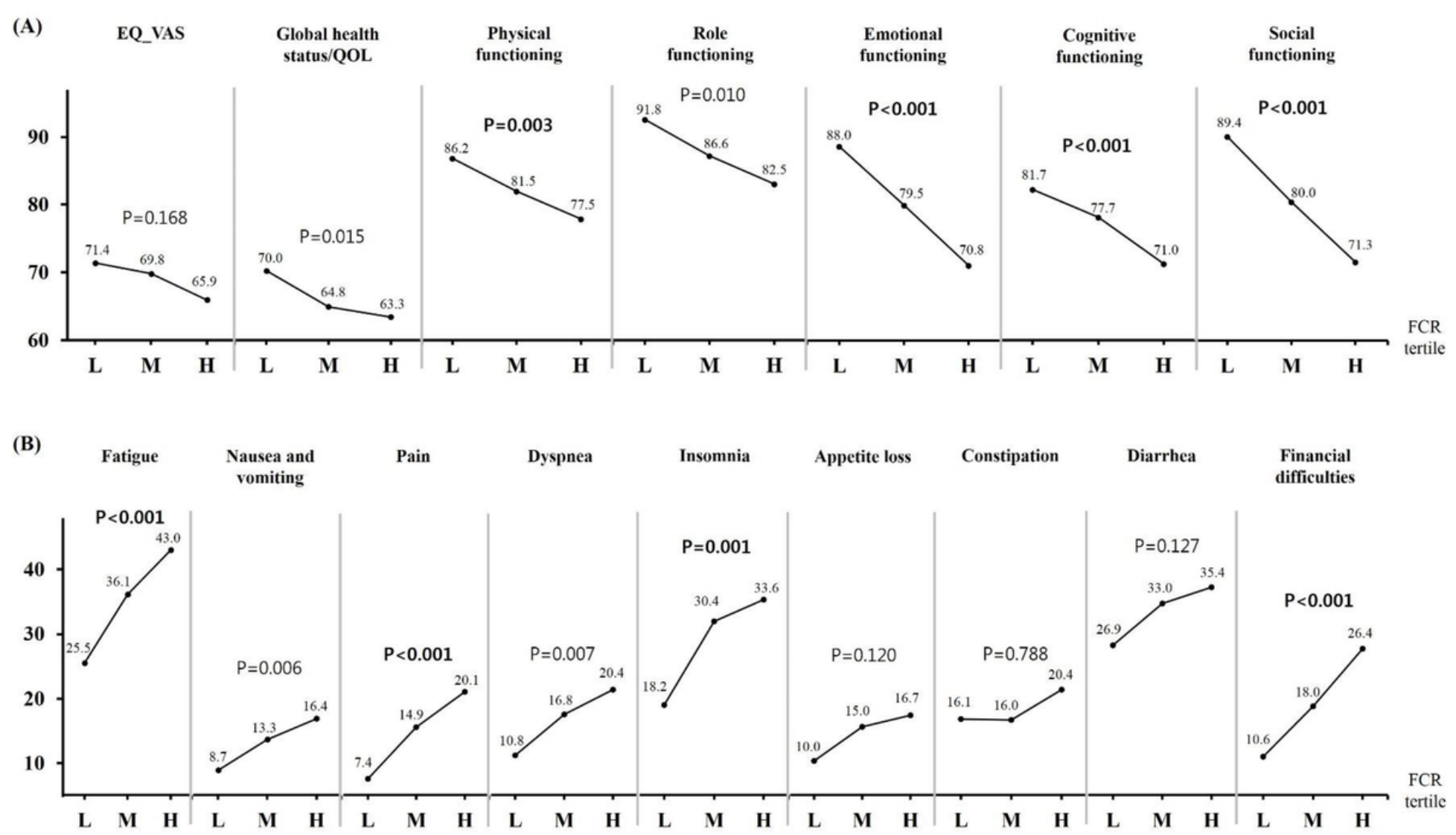

(C)

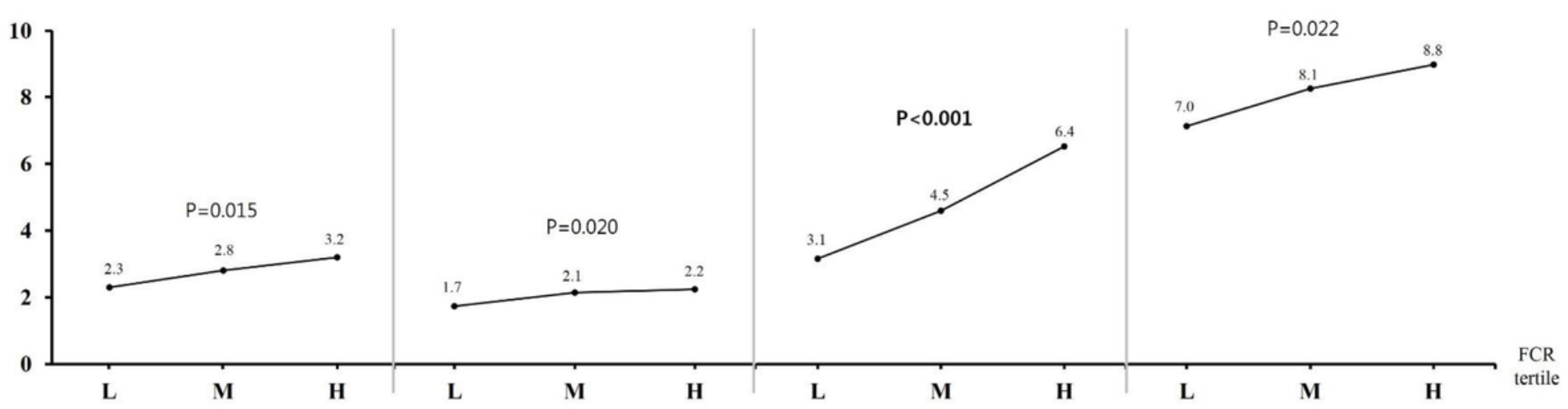

Figure 1

HRQoL, physical, and psychosocial factors according to the level of FCRI Linear regression analysis for trend was performed after adjusting for age, sex, cancer stage, Carlson's Comorbidity Index, time since diagnosis, family cancer diagnosis, Duke FSSQ, and satisfaction for communication within medical team 
and care coordination. L: lowest tertile; M: middle tertile; and $\mathrm{H}$ : highest tertile. QOL: quality of life. A) EuroQoL Visual Analogue Scale (EQ-VAS) and global health status (range: 0-100) and functional scales (range: 0-100) of The European Organization for Research and Treatment of Cancer 30-item quality of life questionnaire (EORTC QLQ-C30). A higher score means a better health status. B) Symptom scales (range: 0-100) of EORTC QLQ-C30. A lower score means a better health status. C) Physical and psychosocial factors related to the FCRI. A lower score means a better health status. 